$N \cup U H$
$O$

U D M P B B HMGR I B D P B L R B F B A ।

X A Y H A S G S NPTZRWQSCGZN J I MNSTK.

A A C L U T C H I M A S T E R T C Y L I N D E R E R N G M J b,

A MOAMOEUANDLNGEUAIOGDNOIPRNGMDSAU,

EKJEKJ I CKO I A GR D C KMNE SWLNCAWZYKFE QLO,

MOTMOTMQOGNVZDSQONVUSGRVLGRAKGEREMS,

$T N U T N U G|N R L E J G D| N E O M N Y A Z T 5 Z N A X \theta)=F Z K M$.

DCODCOSVCESRPMNVCLINEWCI X I S Y Y M ,

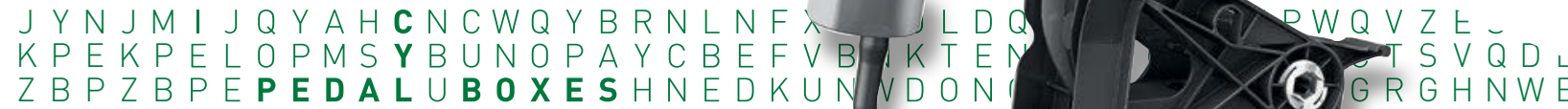

TNETNEHBNZWI DCVBN I OPLKUHG ZCA

CROCROETRWPN IUZTRHGFDLGEN UURT

BEFBEFSHECEDHOKHEUPSKUPPLUL-

SOB S OBP I OSGEZN J I OCVFV FOFETZHN

FE I FE I WREQRRUZTREKJHASN I NROAXE-

CWDA YWTRDXESYWATPHCEEBERZYL INDERZN

P JMR I JHLMOKN I JUHBZGVJOHASEDNKLPSXW

CGTI DGLETUOADG Y Y M M K I J B HUZ DDGVTQUJXRH $J T Z A E T R P W J M C Y F V E G B Z H E \cup J M|K O Q S Y L R T X A G Y|$ VWMKRY AKDWJ E E JKLPOIUZNMIQWOIREUHBZGWRZJFLUJADY $L S J Q D$ E A S EAYVNPIESYSCBFAMHTILQNVXDOORUTEI EKJNC $M O T \vee Q$ $T N \cup Z$ $D C O L V$ $J Y \mid X Q$ N J KL N $A$ A $O$ I U $\cup D M A B$ $A$ A $O$ । $\cup A$ $M O T \vee Q O$ U D M A B FE I SREQ CF V NKFN $P$ J A SREHLVKN I J U HBZGVKREWSPLOCYQDMFEFBSATBGPDBU $C G T J D G L E T U O A D G J L Y C B M X Y M L M O K N I J B H U Z G F D G V T Q U O T R Q$ $J T Z U E T O \mid Z R W Q E T U O M B C Y F V E G B Z H N U J M I K O Q A Y L M R T X A Z Y B$ 


\section{Clutch Release Systems}

\section{From system know-how to a successful volume produced product}

Roland Welter

Tim Herrmann

Sebastian Honselmann

Jeremy Keller

D vv

$J \mathrm{ZMH}<$

$A G Q S W \mid$ t

F I MBCHSEHヒレ

C E C B S T P O I O D C V ז

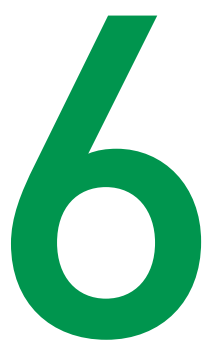

$D G \vee T Q U J X R E L K J H G F D S A \mid v_{\mid} \cdots$

N B MRTXAGYWPHCEQA YWS X E E C K,

R T V N H U I I J B G V T F C R X E S N W S K ᄂ

EHTFLUJADGYCBMWRZ I P S F H K T V N Z L MU,

O I B P ORUTETMBCYNVXADGJLKHESYSCBMBし

XR S KUPOWRWZTWHNEDKUNWPONCA L V I K Z TWH I

GYKLPFLKJKO I UZTREWQYXCVBNM I QWUO।UZTR

B I X A Y HASGSVNPIZRWQSCGZN J I MNSTRVNPIZRWQ_

$A D U K O G I K C K P M N E S W L N C X W Z Y K F E D I O P P M N E S W L N C X$

$T E C Z G Z M Q G O D N V U S G R V L G R V K G E C E Z E M D N V U S G R V L G F$ WRTSLOKZINEXOMNYAZTEWNFX JLRN I FEXOMNYAZTEW $K J O M E P S C \vee C Y I \cdots \cdots \cdots \cdots, 1 / V F H N \vee R D J K U \vee Y L J N E W C L \vee \vee F$ S G MUAN JY O' 'SQFHBQFGOBRELNFXTJC
KCNSRDO
Q GEPN N

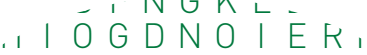

$Z$ I A T B

$C \vee E P r$

$Y$ Q C Z

JNA

$A \cup \vee$

D B N

$A \cup 1$

$O Q$

$\mathrm{D} B$
$D D L R B E F B F \vee N$

. UAH | OGDNO | ERNGM

$O Q O D N V U S G R \vee L G R \vee K G$

P D B D D L R B F B A F V NKF N

O TRELKJHGFDSAMMBVCX $X A Z Y W P H C E Q A Y W S X E E C R F$ I $O U B$ I JBZGVTFCRDXESNWAS U JRDGYCBMWRZ I PSFHKTVN RUTETMBCYNVXADGJLKHES P OWRWZTWHNEDKUNWPONCA $F L K J K O I U Z T R E W Q Y X C \vee B N M$ HASESVNPIZRWQSCGZNJ|M 马 I KCKPMNESWLNCXWZYKF F ' A S U S VNP I ZRWQ SCGZN J I' I KCKPMNESWLNCXWZYKF - OXODNVUSGRVLGRVKG

1. NEXOMNYAZTEWNF

' C Y L JNEWCLVVFH. $\cap N \vee \cup S G R V L G P$ 


\section{Introduction}

More than 100 years after the invention of the automobile, it seems as if the technology of clutch release systems, is a mature one, without the necessity of changes. However, even in this seemingly evolved family of products, the innovation dynamic remains high. Current developments aim to further increase robustness, replace existing materials with polymer materials, and integrate sensors in the master cylinder.

Master cylinders with integrated sensors have only been used in a few cases in the past. The proliferation of systems such as start/stop or the electronic parking brake is now leading some car manufacturers to consider such sensors in the master cylinder as obligatory. The sensors make it possible to measure the travel on the clutch pedal and thus determine the driver's intent.

Materials too are evolving. While for decades cast iron or aluminum alloys were dominant, in new applications, master cylinders, pipes and slave cylinders are almost always made of plastic. Initial problems with the use of polymer materials, such as master cylinder squeaking, high adhesive friction and volume expansion, have since been resolved. The technologies necessary for the use of plastics have been constantly refined and are now solid and economical. Even in double clutch systems, which have higher, continuous loads, plastic cylinders are gradually becoming established. Current developments are focused on using plastic in the pedal box.

Ultimately, the robustness requirements for the components used in clutch operation have risen significantly. Even just a few years ago, one million cycles was the going operating load specification for release systems. Now, it is not unusual to require two to three million cycles - accompanied by increased requirements regarding the ambient conditions of temperature, water and contaminant exposure.

\section{Clutch master cylinder}

Schaeffler's LuK brand currently has three different types of plastic clutch master cylinders in the product line. The difference in the designs is in the seal configuration used.

The clutch master cylinder that is used the most in volume production has a mov-
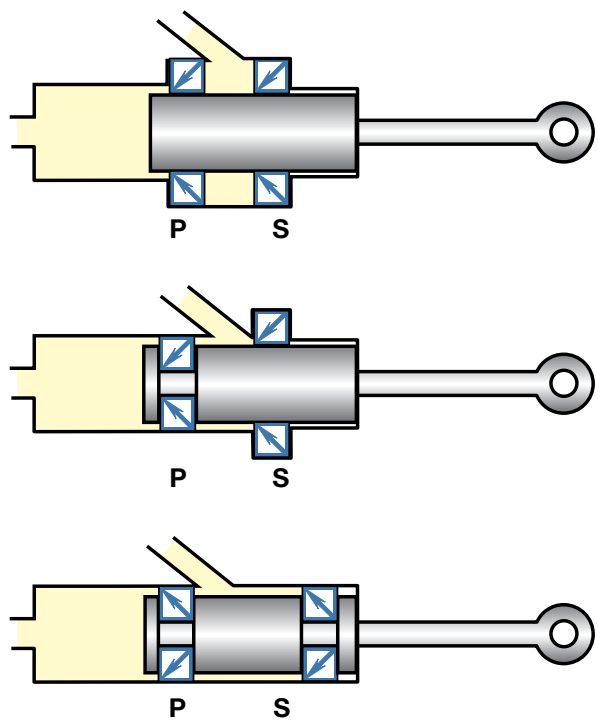

$\mathbf{P}=$ Primary seal

S = Secondary seal

Figure 1 Types of clutch master cylinders 


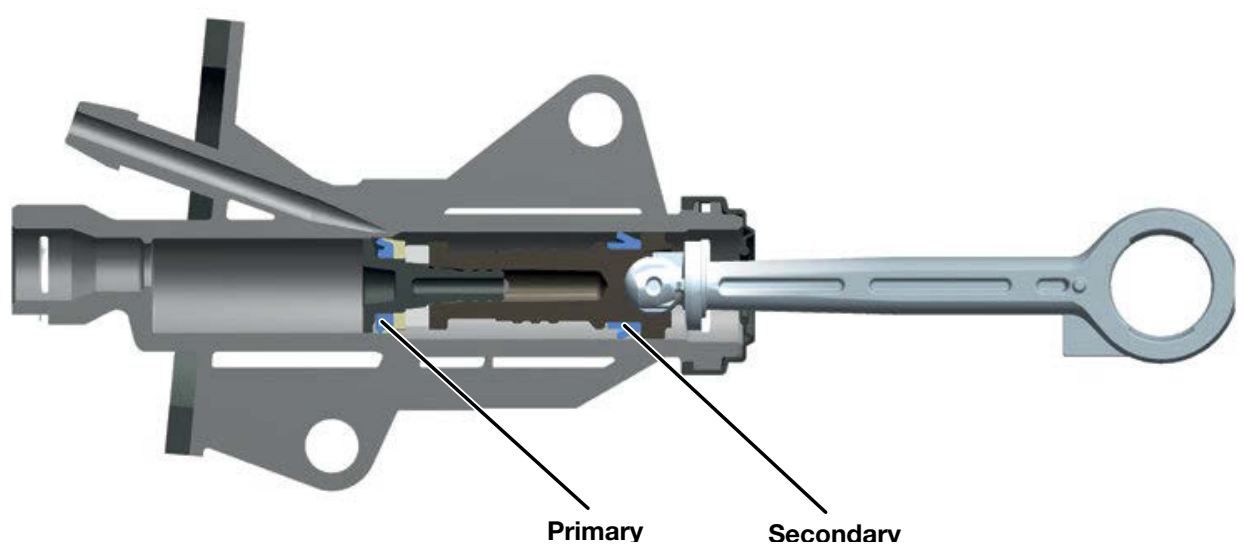

Figure 2 New clutch master cylinder with a one-piece housing and seals mounted to the pistons

ing piston and two stationary seals (Figure 1, top). This configuration allows the primary seal to build up pressure toward the slave cylinder while the secondary seal retains the fluid without pressure in the reservoir. The advantages of this design include the fact that the pistons can be manufactured using a duroplastic material. With this material, the squeaking encountered with the usual seals made of synthetic ethylene propylene diene monomer (EPDM) rubber is effectively suppressed. The disadvantage to this design is that for installation reasons of the seals the housing must be made in two pieces and thus is comparatively more costly to set up. In addition, the entire pressure chamber expands radially during operation, which results in a relatively high volume expansion.

The second design (Figure 1, center) uses a primary seal that moves with the piston and a stationary secondary seal in the housing. The volume expansion during operation is lower due to the smaller pressure space when the piston is pushed in. The disadvantages of this design include the fact that the noise problem has not thus far been satisfac- torily resolved, and that, in addition to the installation of the secondary seal, a costly, two-piece housing is necessary here as well.

In new applications, LuK is therefore focusing on a third variation (Figure 1, be(ow), which has a one-piece housing made of thermoplastic and uses seals that are mounted to the piston. Figure 2 shows an example of the technical design of one such clutch master cylinder.

Seals made of EPDM are generally used, with the primary seal being protected on the outer diameter against the cylinder raceway by a shield made of unreinforced polyamide in order to improve friction and wear. This type of measure is not needed for the secondary seal, which is not under pressure during operation. To prevent squeaking noises with critical brake fluids, seals made of special materials can be used with this master cylinder design.

A well-thought-out test stand system is helpful in researching suitable seal and raceway material combinations for the specific brake fluid. In addition to standardized noise measurements with complete master cylinders, there is a tribologi- 

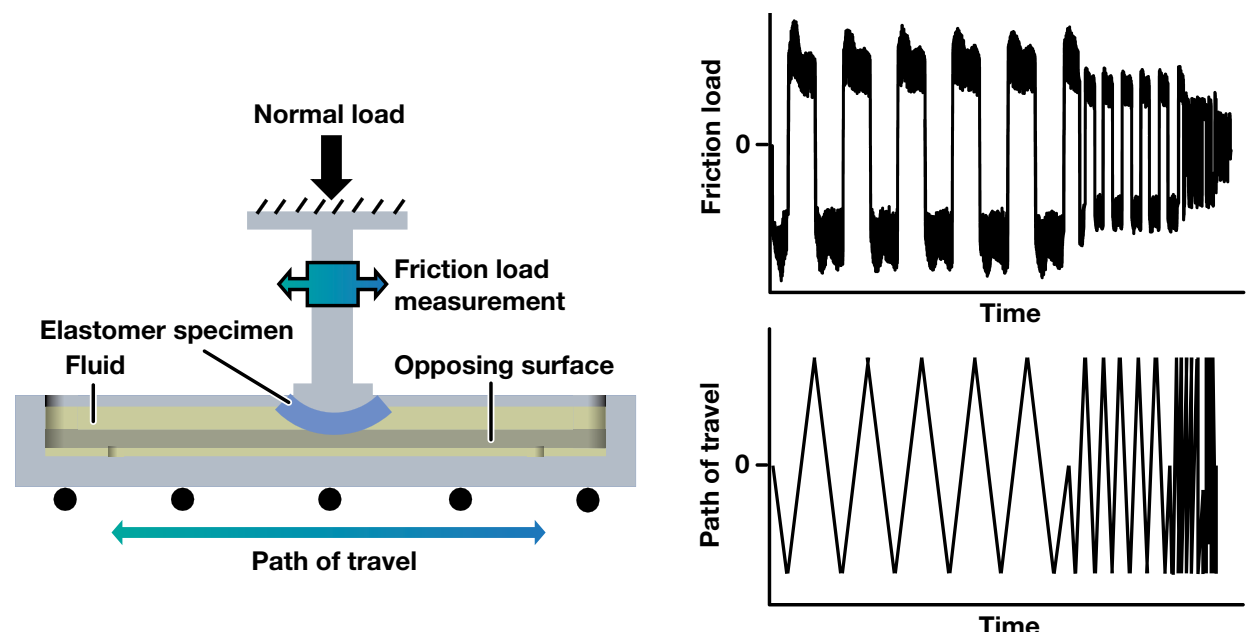

Figure 3 Tribological test stand for basic trials on seal friction and noise excitation

cal test stand available for basic trials that was developed specifically for this purpose (Figure 3).

Current trials on this Tribometer involve mounting and loading a flat specimen made of the raceway material with a seal material specimen, which is pushed along the flat specimen. In the process, the contact points can be flooded with brake fluid and maintained at a constant temperature. Measuring devices allow the friction load and frictional vibrations to be recorded. Suitable material combinations show two clear effects: The gradient of the friction coefficient over the piston speed is small and there is no detectable frictional vibration. Figure 4 shows an example of the contact of polyamide with standard ethylene propylene diene monomer rubber (EPDM) and liquid silicon rubber (LSR).

In all of the trials conducted thus far, LSR has proven itself superior with regard to friction gradient, friction level and friction vibration behavior. There are, however, a few brake fluids on the market, particularly in Asia, that are not compatible with LSR. The goal for future development is to avoid this limitation.
Advantages of the new cylinder design with moving seals include its low volume expansion. This is due to the design, since the highest pressure occurs with the piston nearly pushed in, when the "breathing" cylinder surface is comparatively small. Due to the one-piece housing, static burst pressures of more than 200 bar were achieved with the new cylinder design.

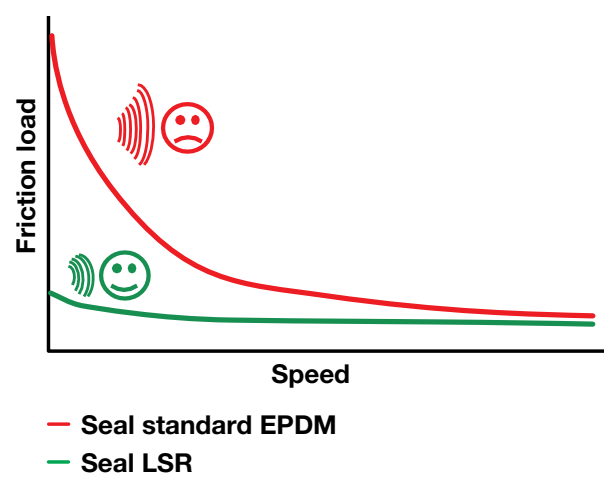

Figure 4 Friction load gradient for an EPDM and an LSR specimen against a raceway made of polyamide PA 66 with fiberglass fill 


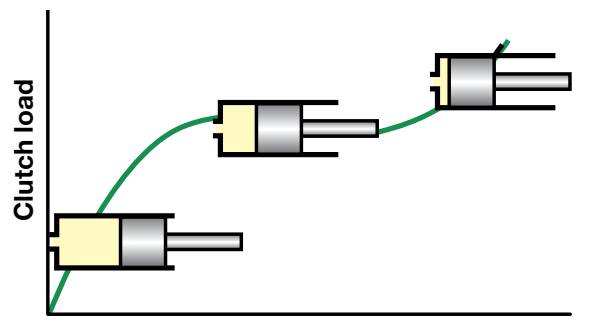

Pedal travel

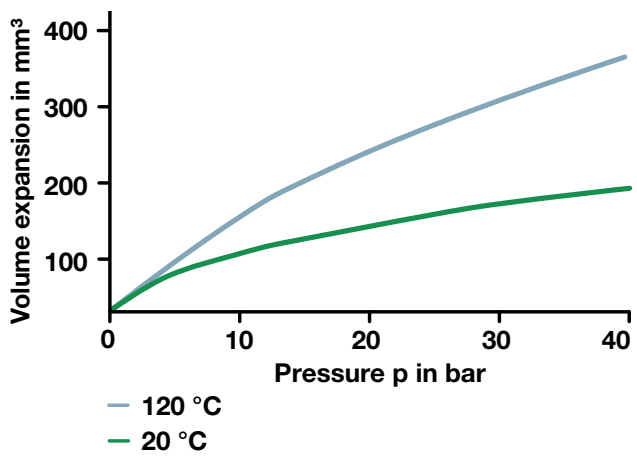

Figure 5 Volume expansion of the new master cylinder

The cylinder can be equipped with additional attachments if desired, such as a premounted bleeding pipe, which is most cost-effective designed as a plastic convoluted tube. In contrast to the seal customarily used thus far for this type of convoluted tube, which has to be greased to attain acceptable mounting forces, a new type of self-locking seal is used. The seals have locking hooks on the adjacent side, which engage into a groove of the convoluted tube during mounting (Figure 6). Additional lubrication is not required. The associated problem of contamina-
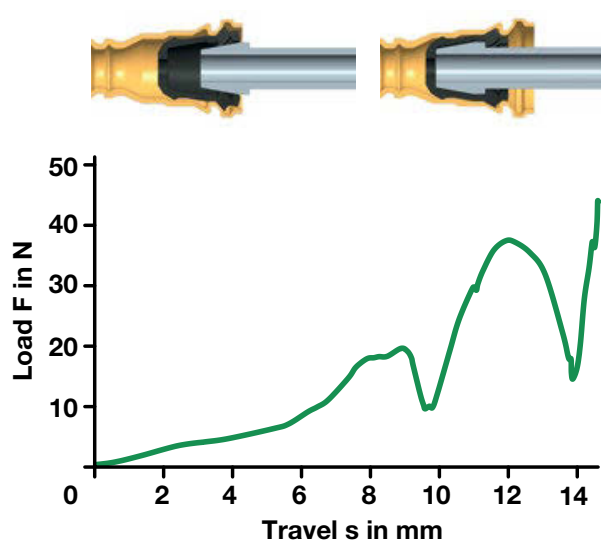

Figure 6 Ergonomically configured connection between bleeding hose and fir tree connection tion is thus eliminated. The mounting forces are $40 \mathrm{~N}$, maximum. The haptic indication of a successful mounting is a noticeable drop in the sliding force. Normal fill pressures during vehicle assembly of up to 10 bar are endured without issue.

\section{Integrated sensor system}

There is currently an increased demand for master cylinders with travel and/or position sensor systems. The travel sensors continuously measure the piston travel and thus replace the potentiometer on the pedal axle, whereas the position sensors generate a digital signal when passing through defined piston positions and thus take over the pedal switch function. Both measuring tasks can take place in one space-saving sensor on the clutch master cylinder. In addition, travel measurement on the clutch master cylinder is less dependent on tolerances and thus more accurate. The sensors used in the clutch master cylinder work exclusively without contact and thus cause no noise or wear. In the meantime, in addition to the familiar Hall sensors, magnet-free inductive sen- 


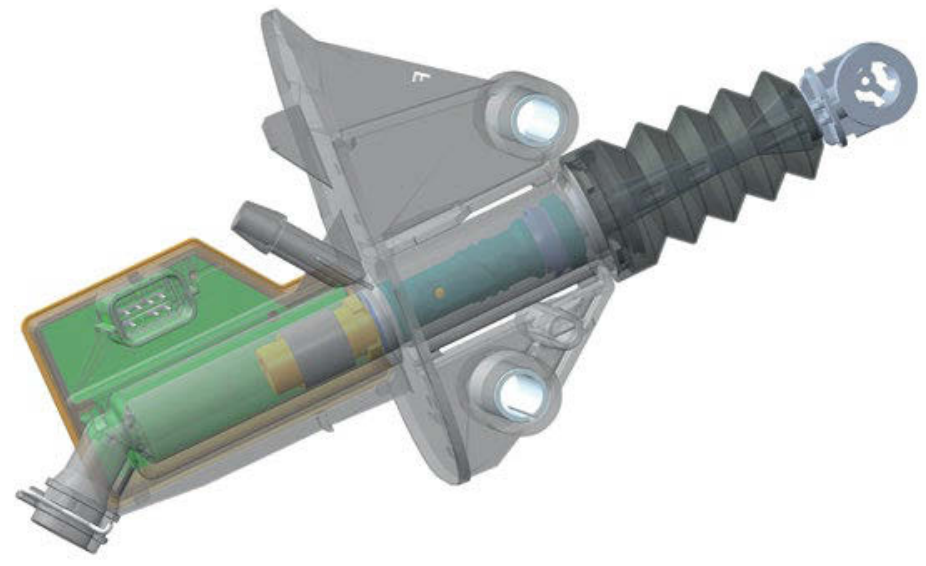

Figure 7 Master cylinder with integrated inductive travel and position sensor

sors integrated into the housing are now also available in volume production, as the example in Figure 7 shows.

The reason for the increased demand for sensor information from the clutch pedal is the need to make travel and position information available to the engine controller or the control units for start/ stop or the electronic parking brake, which allow conclusions to be drawn regarding the engagement status of the clutch as well as the driver's intention. Common functions today are shown in Figure 8.

Additional signal ultilization is conceivable, but are is not yet used on a large scale. Examples include detecting operating errors such as insufficient load release of the pedal when driving, too frequent slipping of the clutch or resetting a calculation model for wear predictions.

Hall switches, integrated Hall ICs for travel measurement as well as magnet-free inductive sensors are used in volume production. The use of intelligent sensors makes it possible to compensate for the tolerances related to production and mounting with a calibration after mounting on the clutch master cylinder. They also
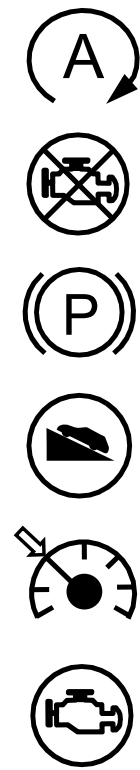

Figure 8

have a certain diagnostic capability. Cable breaks, short circuits and internal sensor errors can be detected in this way and communicated to the controller.

The requirements for the functional safety of electronic components in vehicles according to ISO 26262 are met with design up to level "ASIL C". This is dependent, however, on the specific safety goals of the sensor-related vehicle functions, which must be specified by the automobile manufacturer. Usually multiple pieces of avail-

\section{Early detection of driver intention when disengaging at engine start \\ Preventing engine start for unseparated clutch}

\section{Automatic release of the electronic parking brake}

\section{Controlled start up on hill}

Turn-off of speed controller for clutch operation

\section{Comfort increase from engine} engagement (speed increase) 

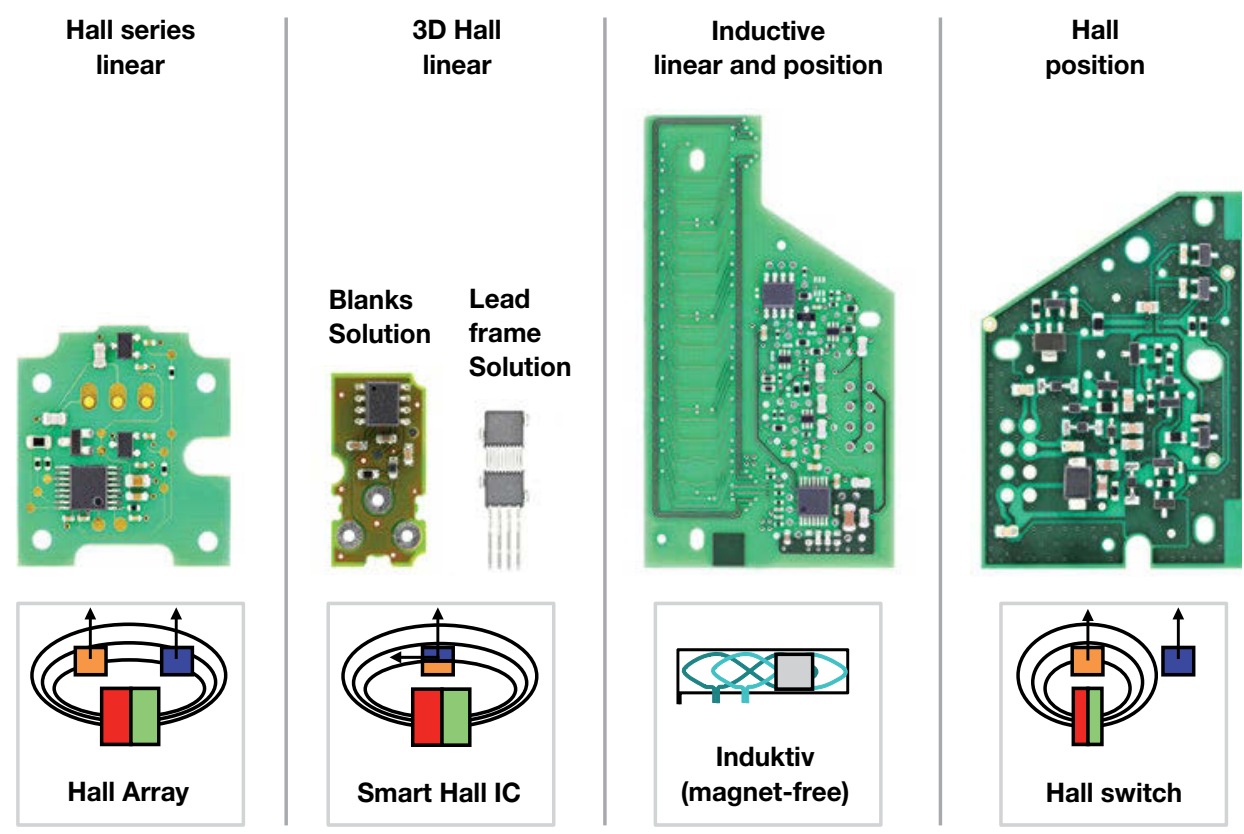

Figure 9 Sensors used in the clutch master cylinder

able sensor information are accessed in order to reach the safety goals at a vehicle level. This reduces the requirements on individual sensors.

One important advantage of the Hall sensors is their short axial installation length, which can be further reduced in the future. Thus, Hall array sensors use two Hall cells connected one behind the other and signal processing via a microcontroller. Highly integrated chips use multiple Hall elements, which make it possible to measure the magnetic field in multiple dimensions and derive travel information. In miniaturized form, these sensors no longer have boards, but rather are all mounted directly on the lead frame together with the necessary circuit. The price of the advantage of a small installation space is that additional circuits or custom solutions are not possible.
Development goals include reducing the mass of the magnets and minimizing the proportion of rare earths. While cylindrical magnets were used originally, LuK is increasingly switching to segment magnets and using an anti-rotation device for the pistons. In the Hall switch-point sensor, the magnet has now been reduced to a small cube.

Despite these advances, efforts are being made in newer solutions to completely eliminate the use of magnets in order to circumvent the price volatility for rare earths. One initial result of these efforts is a contact-free inductive travel sensor that uses a small aluminum ring as the measuring element. Higher precision can be achieved with this type of system than with a Hall sensor, and additional switch points can be derived from the signal of the integrated controller or from an additional switch as needed. 

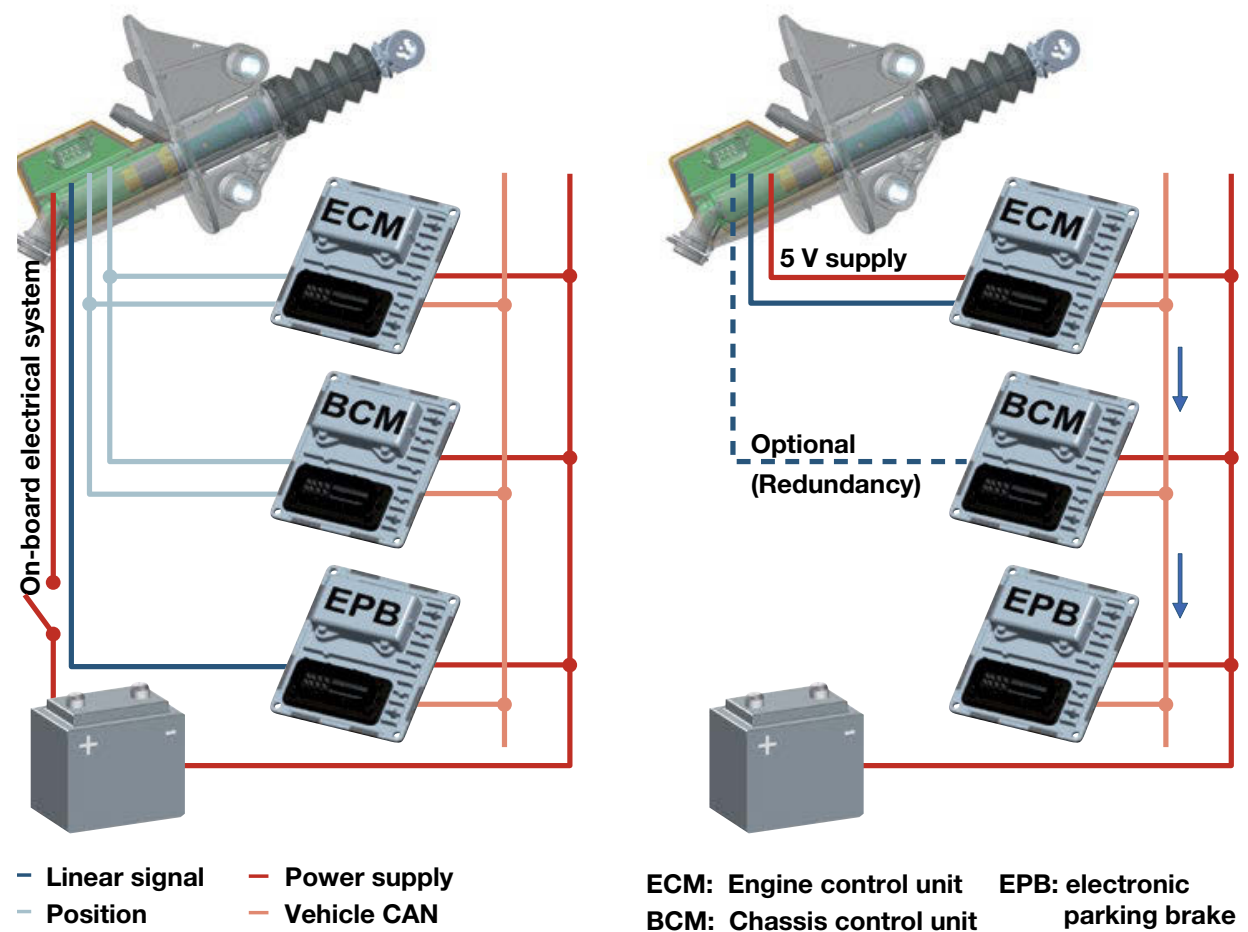

ECM: Engine control unit $\quad \begin{aligned} & \text { EPB: electronic } \\ & \text { BCM: Chassis control unit }\end{aligned}$
parking brake

Figure 10 Master cylinder signal processing in the vehicle; left: commonly used today; right: future concept

The only disadvantage to the inductive solution is the comparatively large installation length. The length of the coil system, depending on the design, can be up to $135 \%$ of the measured travel. This poses no problem for most applications. Nevertheless, LuK is working on shorter installation solutions, but they are not yet production-ready.

Highly integrated sensors emit a travel signal as well as position signals and provide this information to different controllers. Since the signal interfaces and the expected voltage levels are not uniform, and the on-board electrical system is the only available power supply, the full potential of an intelligent sensor solution cannot be completely realized at this time.
Since, in contrast to the linear travel signals, the position signals are not available from active diagnostic functions, safety goals according to ISO 26262 are often not completely met at vehicle levels with position points derived from the linear travel signal. For applications with high safety requirements, LuK therefore recommends using a travel sensor with two independent travel signals, which are processed by the respective controllers and which can be compared as needed for increased safety. A stabilized $5 \mathrm{~V}$ power supply is provided in this case by a controller and the sensor signals are preferably provided as pulse-width modulation (PWM) or as digital signals (for example SENT). One advantage of this solution is that the information needed for different 
vehicle functions is derived directly from the linear signal and can be transmitted via CAN bus to the respective controllers. The first manufacturers are already planning to use this concept.

The travel measurement via integrated sensor system can also be used for clutch-by-wire applications. To this end, a broad spectrum of more or less complex solution suggestions are being discussed. LuK favors a solution in which only the conventional master cylinder in the pedal box is replaced by an element with similar installation space. This could consist of a housing with a piston rod and interior spring assembly. A spring with a linear characteristic curve is eclipsed by the spring and hysteresis effect of a clamping element and ensures the usual plateau of the clutch operation. The sensor is on the outside of the housing in this design, the same as with the conventional master cylinder.

\section{Clutch pipes and installation elements}

Pipes have the task of transferring the hydraulic pressure safely and with as little friction and volume loss as possible. In addition, pipes are supposed to prevent engine vibrations propagating as far as the pedal box. Installation elements such as dampers and anti-vibration units are used for this.

Pipes are currently made of steel/rubber or polyamide (PA 12 and PA 612) materials. Currently, pipes made of plastic are becoming increasingly common because of their low costs [1]. LuK now uses PA 610 for almost all pipes. This plastic is more than $60 \%$ based on plant raw materials. The global availability of prematerials is better than for PA 12 and PA 612. The

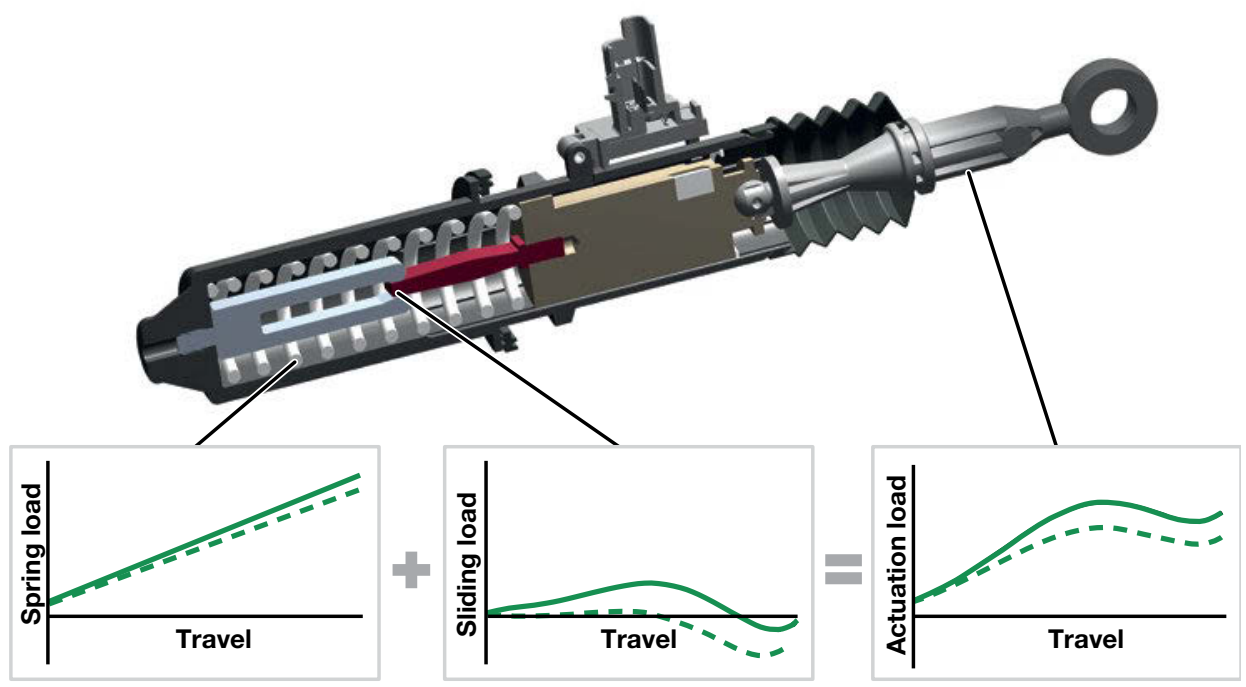

\section{- Disengage \\ -- Engage}

Figure 11 Compact pedal load emulator with sensor for clutch-by-wire systems 


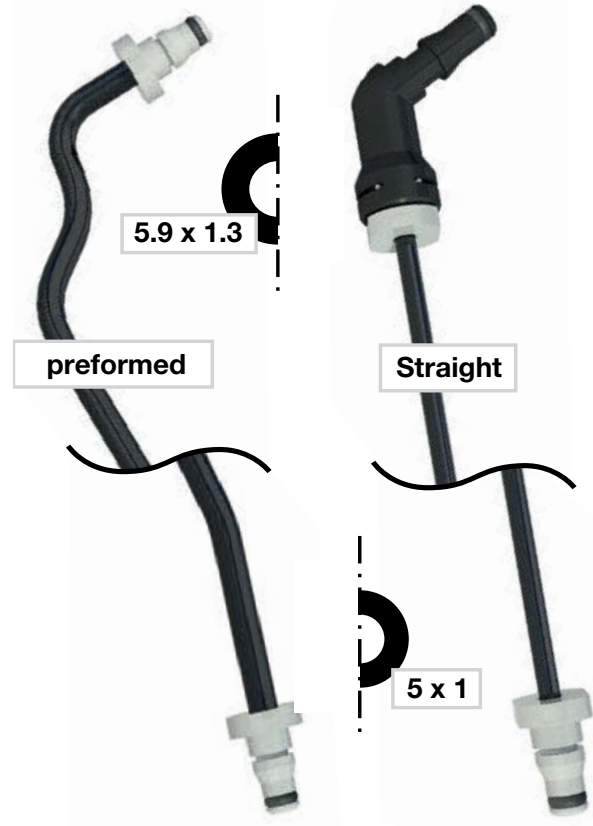

Figure 12 High Pressure Pipes made of PA 610 for clutch operation mechanical properties are almost the same as for PA 612 and the chemical compatibility is better.

Plastic pipes in vibration-critical applications (diesel engines and engines with few cylinders) mostly require the use of a filter to counter pedal vibration and interior noises. This filter traditionally operates like a soft added volume in the pipe. However, this regularly caused a conflict between good filter effect and low-loss direct operation.

Due to the complexity of this conflict of interest, an optimal solution was very hard to come by in testing. Therefore, specialized simulation tools had to be used. In general, it is sufficient to calculate the transmission behavior of the pipe within the frequency range. For this purpose, LuK has the PipeSim program, which calculates the flow and vibration behavior in the pipe based on the numerical solution of the Navier-Stokes equations.

\section{Calculation application Flow profile}
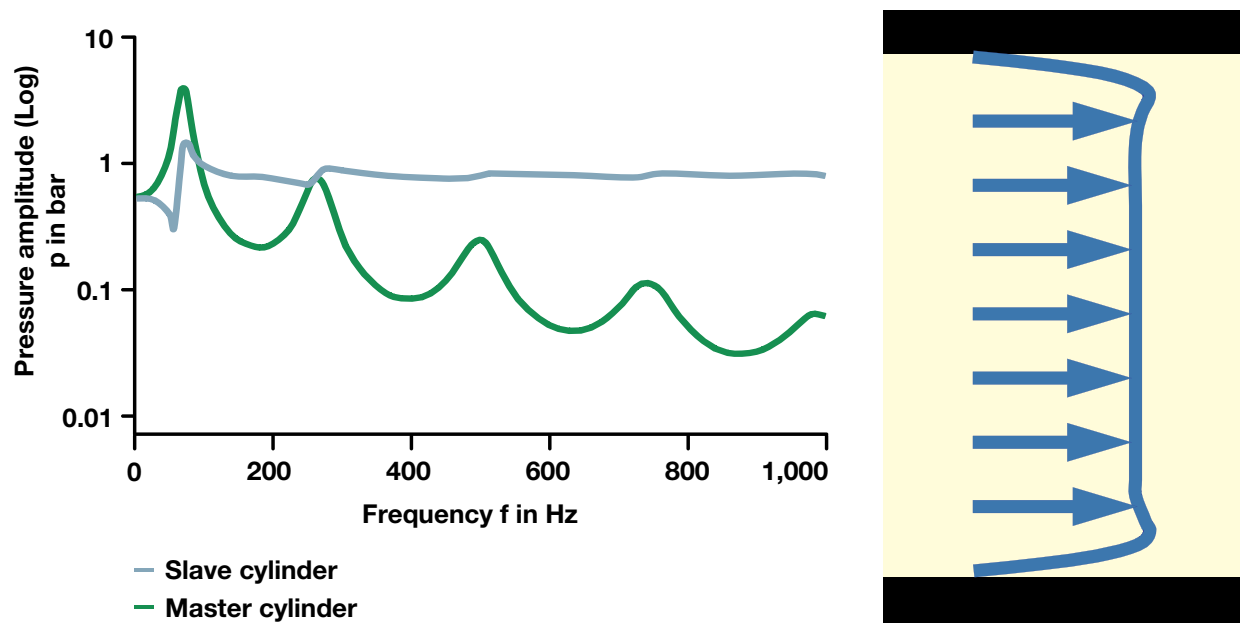

Figure 13 Simulation of the transmission behavior of clutch pipes and built-in vibration dampers 


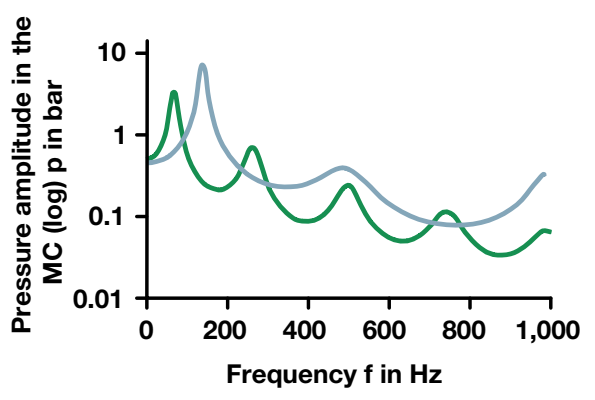

- Steel / rubber

- Polyamide
Slave cylinder Master cylinder

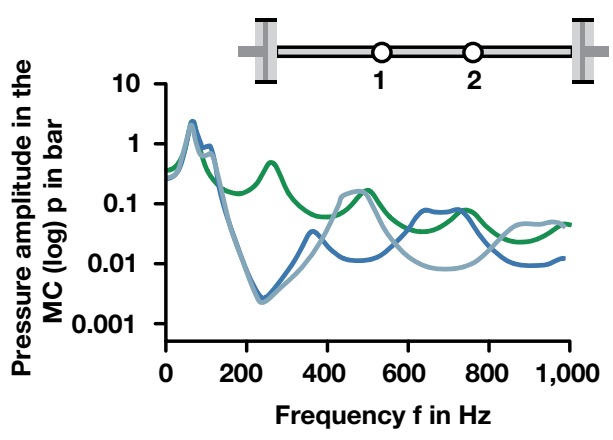

- Without damper

- Without damper

- Damper in position 2

Figure 14 Example of a variation calculation using PipeSim

PipeSim helped in carefully studying the vibration transmission up to the master cylinder and identifying the best corrective measures. This generally involves a vibration damper with appropriate tuning, an anti-vibration unit or a combination of the two at an optimal point along the pipe. The simulation also allows for early determination of the pipe routing, which is available even before test vehicles.

The following example shows the procedure and the advantages of the simulation: The pipe is first divided into multiple segments based on its mechanical design. An excitation is then specified as a frequency curve via the slave cylinder. Based on the transmission behavior of the line, this generates a corresponding pressure vibration in the master cylinder. The diagram of the results is shown in Figure 14 on the left; the black line shows the curve for a steel/rubber pipe and the red line shows a typical PA pipe: The steel/rubber variant exhibits a resonance of the incoming vibrations at approx. $150 \mathrm{~Hz}$. Problems with pedal vibration can be expected there. The pressure curve over the frequency for the plastic pipe is largely lower, but there are also several potential resonances. In the example shown, only the resonances at approx. $250 \mathrm{~Hz}$ showed as unpleasant in the vehicle. This can be countered by installing a vibration damper, whose optimal placement can be calculated using PipeSim.

The technology for the damper and anti-vibration unit could be improved considerably, to a certain extent as a side effect of the simulation technology: These elements can be adjusted perfectly and individually to the respective application. They only show a minimal volume expansion which does not disrupt the pedal characteristic curve and are available as modules. The anti-vibration unit (AVU) in Figure 15 left is, from a hydraulic perspective, a type of mutual automatic shut-off valve when the pedal is depressed, or a restrictor in case of light flow. It is used to counter low-frequency pedal vibrations up to approx. $150 \mathrm{~Hz}$, which can be felt by the foot as vibration. The vibration damper in Figure 15, center, was based on a Helmholtz damper in the gas dynamic. This involves a resilient capacity with a defined restriction as a cross connection to the 

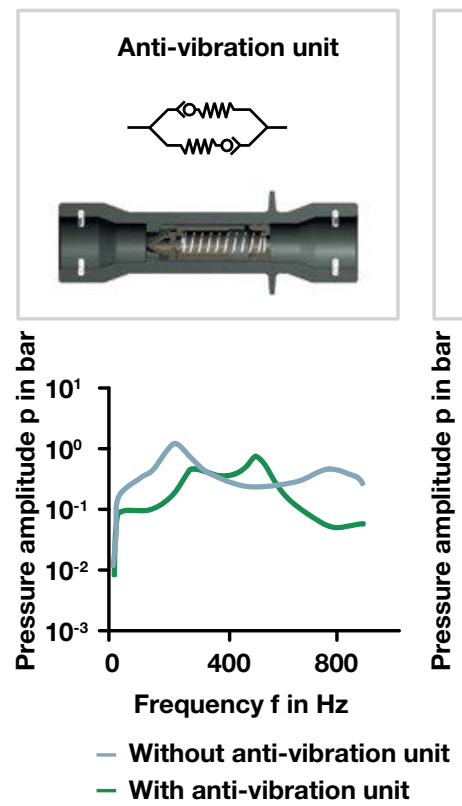

- Without anti-vibration unit
- With anti-vibration unit
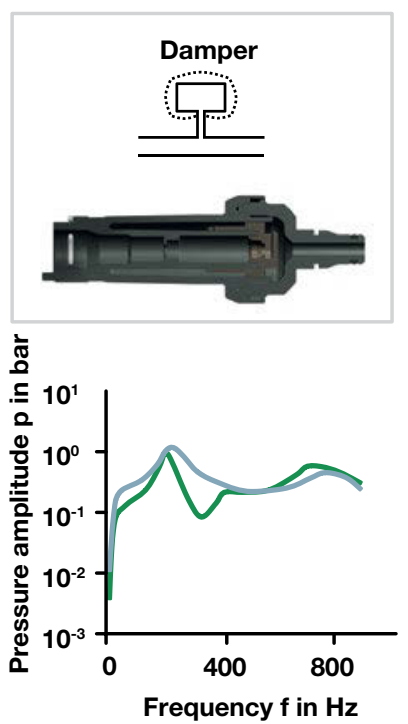

- Without damper

- With damper
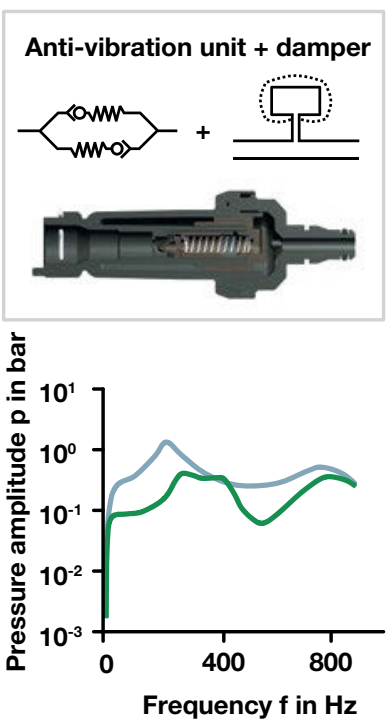

- Without anti-vibration unit + damper

- With anti-vibration unit +damper

Figure 15 Anti-vibration unit and modular system of vibration dampers

pressure pipe. The effect is used more in the high frequency range and serves to counter interior noises. The volume expansion of the connected capacity as well as the length and the diameter of the restrictor determine the damper frequency and the bandwidth. The goal is to keep the volume expansion as low as possible in order to minimize release travel losses. Thus the damper is adjusted specifically for each application. A combination of anti-vibration unit and damper is shown in Figure 15, right. There, the damper is tuned so that the resonance, at approx. $550 \mathrm{~Hz}$ from Figure 15, left, is corrected. Thus far, this approach has been successful in practically all cases, even difficult problems, by using a combination of plastic pipe and corresponding filter. This is an argument for further substitution of steel/rubber pipe with cost effective plastic solutions.
In addition to the vibration dampers, the installation of other elements is possible in the pipes. Examples include ventilation aids for long and non-continuously sloped pipe such as are needed for rearwheel drives. For these types of installation situations, a double pipe and two supply reservoirs have often been used thus far. Ventilation assistance makes this double design superfluous. The small hydraulic stage allows air bubbles to move only toward the master cylinder even if the line is partially tilted away from it. The air thus collects at the highest point of the ventilation aid, is mostly transported toward the master cylinder during engagement and can be discharged via ventilation holes. 

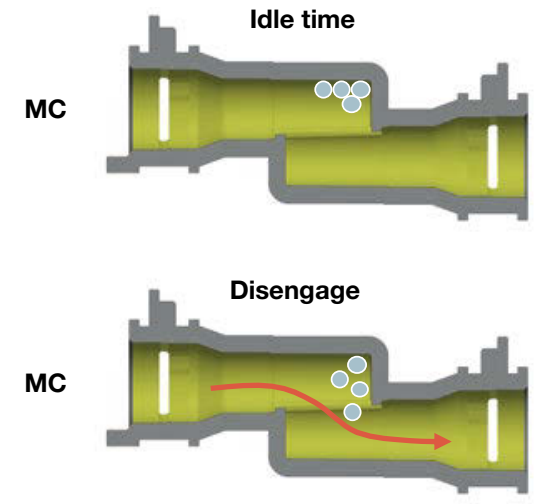

SC

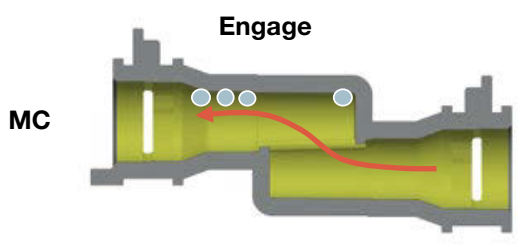

SC

\section{MC: Master cylinder $\longrightarrow$ Direction of flow \\ SC: Slave cylinder}

Figure 16 Ventilation aid for clutch that slope downward to the master cylinder
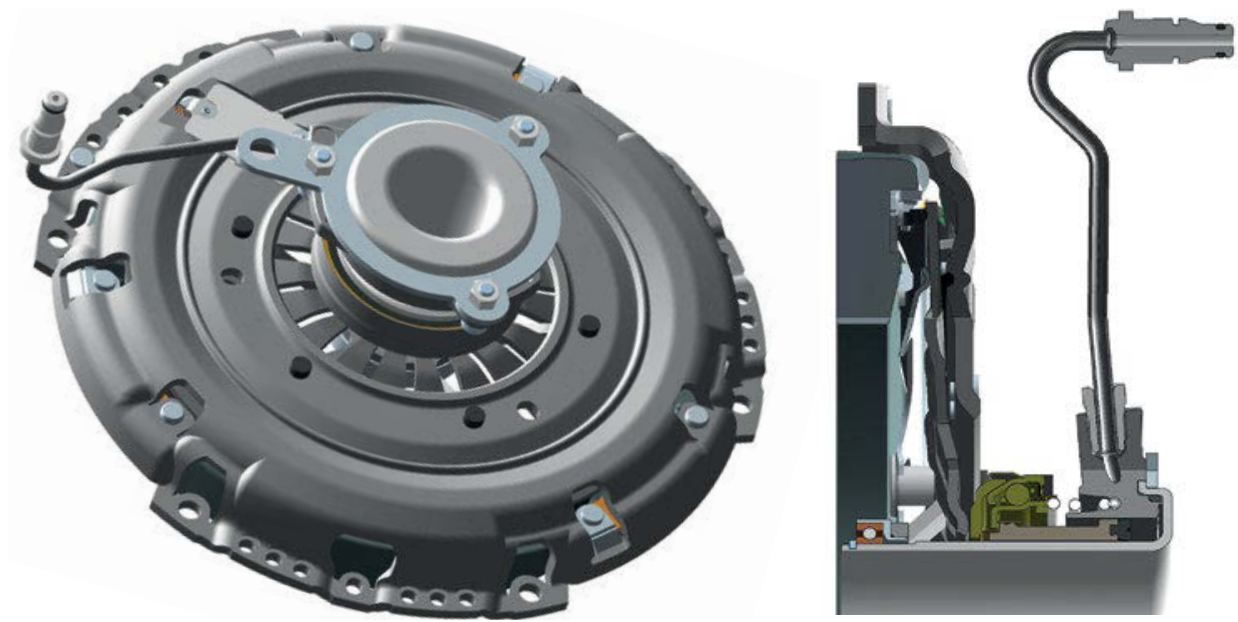

Figure 17 Travel adjusted clutch (TAC) and cover-mounted release system (CMR) with smaller cover bearing on the end of the guide sleeve [2]

\section{Slave cylinder - plastic prevails}

Prior years show a clear trend worldwide toward concentric slave cylinders (CSC) and toward housings made of temperature-resistant plastic for practically all passenger cars and light utility vehicles. The advantages of CSCs include its compact design, uniform bearing load and reasonable price in comparison to all of the other systems. Technical further developments allow for a continuous increase in reliability. Core topics in the development are protection of the hydraulic system and the bearing from contamination, extended service life of the central seal up to three million cycles and constantly low friction. Almost $100 \%$ of all new CSCs for manual transmissions are now built with plastic housings. A detailed technical description is provided in [3]. 


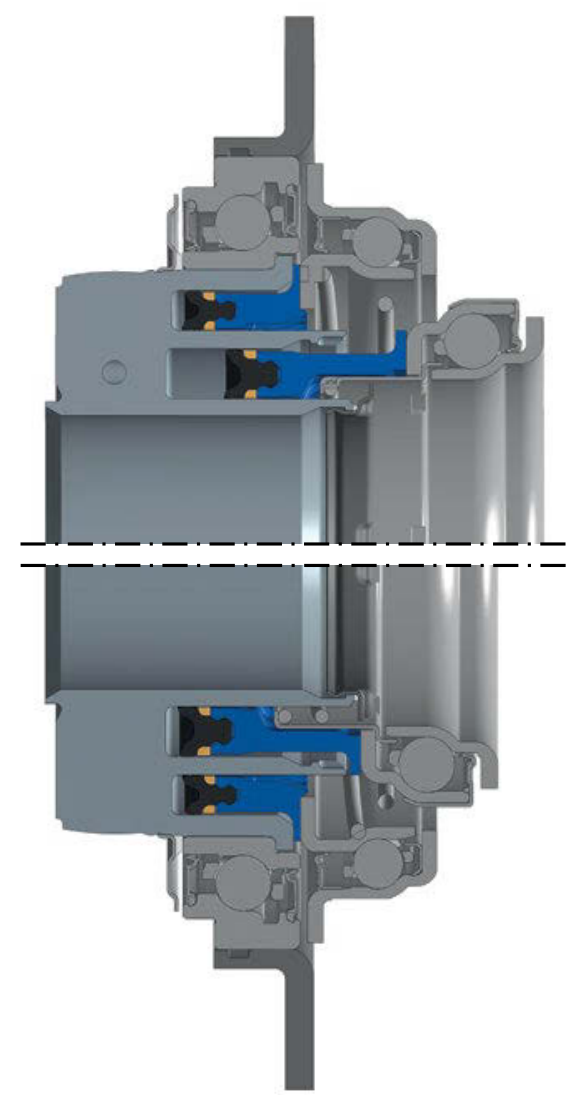

Figure 18 Cover-mounted release system for double clutch

The cover-mounted release system (CMR) presented earlier is now running in initial applications including in volume production and presents comfortable driving behavior with regard to pedal vibrations, slip and judder. Further developments of the CMR focus on reducing the size of the cover bearing and a combination with the new clutch with travel-controlled wear adjustment (Travel Adjusted Clutch, TAC ). The smaller cover bearing should save money and space. The CMR with TAC is configured such that a conventional release cylinder or a CMR can be used with the same cover tool. This provides the customer maximum flexibility for volume production.
The proven technology for the manual transmission is, to some extent, now being transferred to the double clutch transmission with hydraulic actuation and expanded upon. Thus, CSCs for double clutch transmissions now use the reinforced seal, permanent lubrication to reduce friction and the CMR technology. Additional enhancements include:

- Piston with universal joint for parallel lift-off of the clutch,

- Drag torque secured to the housing via springs instead of a pre-load spring

- Dimensioning of the engagement bearing for constant high loads.

\section{Pedal boxes - wallflowers with great potential}

Pedal boxes for the clutch operation are increasingly being used separately from the brake and driving pedal. This topic would therefore also be of interest to a clutch system manufacturer. Current activities at LuK involving pedal boxes include a design simplified by integrating the sensor system, lightweight construction by a direct use of plastic with an integrated master cylinder and, last but not least, the most ergonomic pedal characteristic curve possible.

The pedal box structure is simplified considerably by the possibility of integrating the sensor system in the master cylinder. Thus far, three switches and a potentiometer with corresponding retainer, stops and cables have been used in an extreme case. When using a sensor in the master cylinder, these components can be completely omitted except for one cable. The measurement precision of the system is increased at the same time. 
State of the art

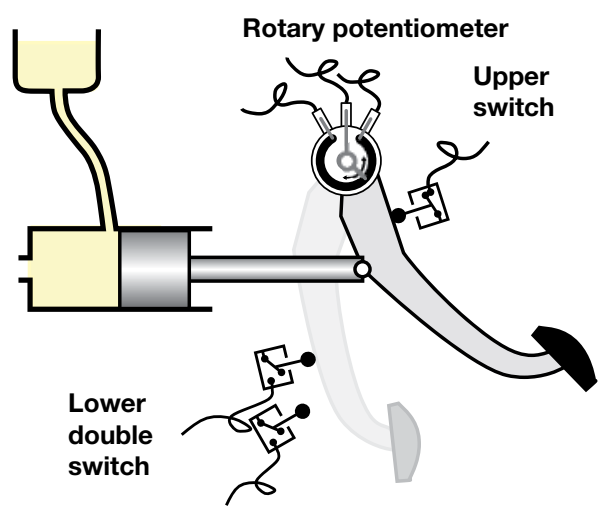

LuK technology

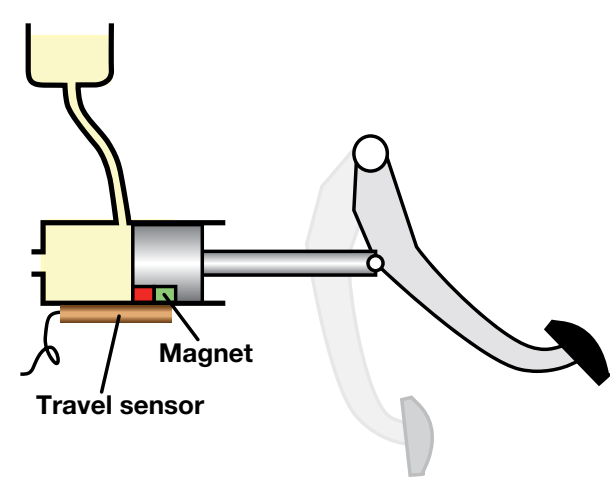

Figure 19 Simplified design of the pedal box by integrating the sensor system in the master cylinder

From a material technology perspective, it is conceivable to manufacture the above new type of master cylinder as one part with the pedal box housing using plastic injection molding. This reduces the assembly ex- pense and increases the stiffness by eliminating the joints. Even the pedal would be manufactured from plastic for this type of solution. In the example shown, there are two possible joint points between the pedal and pedal box. As a

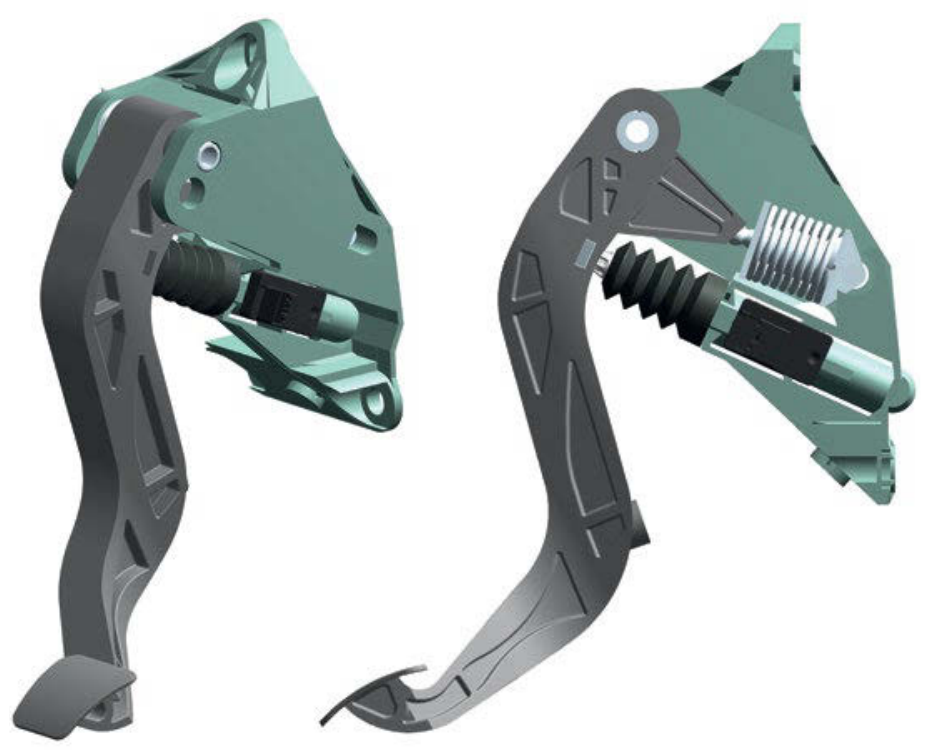

Figure 20 Pedal box for clutch operation made of plastic with integrated master cylinder and sensor result, two different ratios can be used in the same structure. The spring is configured as a cylindrical coil spring and mounted in the middle, covered by the housing. The sensor is mounted on the side of the master cylinder or integrated in the structure.

An ergonomically perfect design of the loadtravel characteristic curve on the pedal is indispensable [4]. Various automotive manufacturers are pursuing 

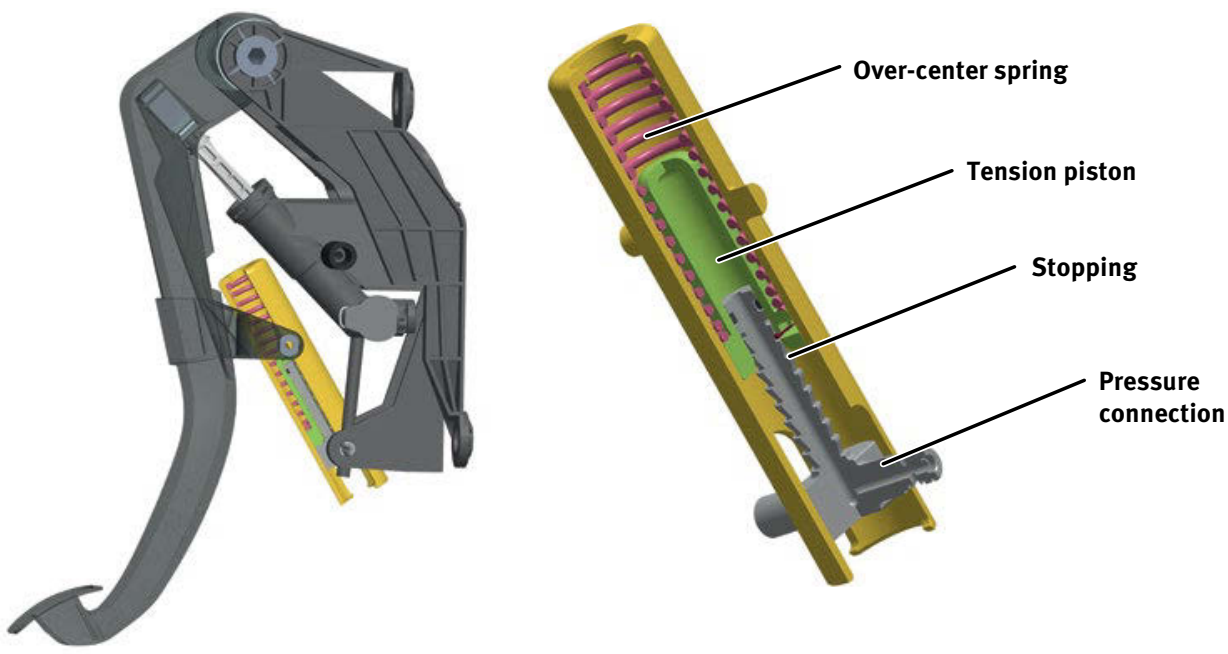

Figure 21 Pedal box with self-adjusting OCS for pedal effort limitation

the goal of reducing tolerance-based load fluctuations in conventional systems in new condition. The idea behind this is to create a brand-specific pedal feeling. Since this is not sufficiently feasible due to tolerance limitations, LuK is posed with the task of studying an adjustment mechanism in the pedal box. Two adjustment mechanisms were considered for this: An adjustment of the pedal ratio as well as a preload of the over-center spring (OCS).

Finally, the idea to make changes to the pedal transmission was proposed because this also changes the travels on the pedal or on the release bearing. The adjustment of the preload of the OCS offers an elegant option for influencing the load level. This makes a manual or automatic adjustment equally conceivable. The manual adjustment could, for example, be made by a simple setting screw on the pedal and a measurement of the pedal effort in the vehicle could be taken. Since this type of step is not provided for in the vehicle assembly lines, LuK is focusing on the automatic setting. For this, the base point of the OCS is acted upon via a small hydraulic cylinder with the pressure from the release system. In new condition, the OCS is unloaded, and thus compensates very little. With maximum pedal effort or increasing pressure in the system, the spring is preloaded further until a balance is reached between spring load and pressure. A mechanism for engaging prevents the tension piston from resetting.

In this way, the complete form of the characteristic curve is not adjusted to a set curve, although the height of the maximum load is. The form of the automatic adjustment shown has the side effect that force increases in the operation can be prevented in part. In this way, wear adjustment is also achieved within a certain range. If a clutch repair is needed, the stop mechanism is triggered and the automatic adjustment starts over. Details on this mechanism are currently being developed; the target application is in vehicles with conventional clutches. 


\section{Summary}

There are numerous starting points for innovation in what appears to be the mature field of release systems. New sensors and pedal boxes with integrated master cylinder made of plastic promise numerous advantages for future volumeproduced vehicles. In addition to an increase in functionality for customers, there is also a benefit from the lightweight design and savings in fuel consumption.

\section{Literature}

[1] Welter, R.; Wolf, B.; Ineichen, L.: Leitungssysteme für die Kupplungsbetätigung. VDI Reports no. 2139, 2011, pp. 231-240

[2] Welter, R.; Wittmann, C.; Hausner, M.; Kern, A.; Ortmann, S.: Deckelfester Zentralausrücker für Kupplungen. VDI Reports No. 2206, 2013, pp. 67-79

[3] Welter, R.; Lang, V.; Wolf, B.: Clutch Operation; $9^{\text {th }}$ Schaeffler Symposium, 2010, pp. 61-74

[4] Zink, M.; Hausner, M.; Welter, R.; Shead, R.: Clutch and Release System; $8^{\text {th }}$ LuK Symposium, 2006, pp. 27-45

Open Access. This chapter is distributed under the terms of the Creative Commons Attribution Noncommercial License, which permits any noncommercial use, distribution, and reproduction in any medium, provided the original author(s) and source are credited. 